\title{
Is irradiation a justifiable treatment of choroidal melanoma? Analysis of published results
}

\author{
W A MANSCHOT' AND R VAN STRIK \\ From the Institutes of 'Pathology and 'Biostatistics, Erasmus University, Postbox 1738, 3000 DR Rotterdam, \\ The Netherlands
}

SUMmARY Analysis of the literature shows that dissemination of choroidal melanomas generally occurs after the $7 \mathrm{~mm}$ diameter stage, that doubling times of uveal melanomas vary from 30 to 365 days, and that death from metastases occurs 30-40 doubling times after dissemination. Tumour related death within three years after therapy is caused by pre-existing metastases. Survival rates for less than four years after therapy are therefore irrelevant in evaluating the efficacy of therapeutic regimens. Considerably higher postirradiation than postenucleation death rates after a mean 10-year follow-up period have been reported, and this difference can be explained by (1) a reported mean clinical tumour regression rate of $31 \%$ two years after irradiation and (2) histopathological studies which revealed that 42 out of 43 irradiated melanomas contained viable tumour, while only $50 \%$ showed necrosis. The doubtful value of preserving vision does not justify the high risk of avoidable death from metastases in irradiated patients.

The purpose of this paper is to present an analysis of the published survival statistics of patients after irradiation of a choroidal melanoma, now that sufficient time has elapsed for the accumulation of reliable data. This analysis has led to the following introductory considerations: (1) almost all survival statistics after enucleation are based on follow-up periods of 10-25 years or until death; (2) almost all survival statistics after irradiation are based on follow-up periods of a few months to no more than three to four years, despite the fact that much more time has elapsed since radiotherapy has been employed; (3) communications on survival statistics after irradiation never mention that a follow-up period of less than four years is irrelevant with regard to the influence of the irradiation on the survival rate.

\section{Time between dissemination and metastatic death}

Collins et al. ${ }^{\prime}$ stated that death from metastases cannot occur before 35-40 doubling times after dissemination. A doubling time is the necessary time for a primary tumour or a metastatic tumour to double its volume. Rümke et al. ${ }^{2}$ and Rampen ${ }^{3}$ measured the increase in size of skin melanomas and calculated the doubling times: they reached values in Correspondence to Professor W A Manschot. the range 20-266 days. Most uveal melanomas are more slowly growing tumours than skin melanomas, and plausible assumptions have been advocated, ${ }^{4}$ and accepted, ${ }^{5}$ that the doubling times of uveal melanomas range from 30 to 365 days. This implies that the shortest possible interval between dissemination from a uveal melanoma and death from metastases is three years. This interval may extend to more than 30 years. Therefore death from metastases within three years after any form of therapy was started must have been due to metastases which had been present before this therapy. Differences in survival rate, when two forms of therapy are compared might thus, after five years, provide an indication of the effect on survival by these therapies, but 10 -year or longer follow-up periods are needed to achieve decisive arguments in favour of a certain therapy.

Gass $^{6}$ reported the first calculated doubling times of choroidal melanomas. He found in seven patients with clinically enlarging tumours which necessitated enucleation a wide spectrum of doubling times, which ranged between two and 30 months. In 14 cases of slower growing melanomas which were observed and the eye not enucleated a much larger range of 10-135 months was calculated for the doubling times. Gass assumed that part of the latter group of tumours 
were naevi. He admitted that there are important limitations to the clinical measurement of changes in size and volume of intraocular tumours. These limitations can easily be demonstrated in histopathological slides by the presence of lengthy, nonelevated intrachoroidal extensions of choroidal melanomas.

Most melanomas studied by Gass appeared to grow at a relatively constant rate, consistent with that predicted by Gompertzian curves of exponential growth. Gass stated that his findings did not support the conclusions of Zimmerman and colleagues that enucleation is responsible for deaths from metastases. He emphasised that his findings argue against one of the fundamental assumptions by Zimmerman et al., ${ }^{7}$ namely, that all melanomas have a relatively uniform slow growth rate prior to enucleation. According to Gass's figures death from metastases does not occur before 6.6 years after dissemination, because his shortest doubling time was 2 months. It is possible that a shorter calculated doubling time would have been found if a larger series of patients with clinically enlarging tumours had been studied.

\section{Stage at which dissemination starts}

We still do not know at which stage a choroidal melanoma develops the capacity to metastasise. This stage can, however, be derived with a high degree of certainty from two American reports ${ }^{89}$ on the survival rates of patients treated by enucleation for small melanomas in the $<7 \mathrm{~mm}$ and $<10 \mathrm{~mm}$ diameter groups. In both series the size had been assessed by histopathological examination. The tumour related death rate of all patients with a melanoma in the $<7 \mathrm{~mm}$ diameter group was nil, while death rate from metastases of patients with a melanoma $<10 \mathrm{~mm}$ was $22.7 \%$ after 10 years in the first series ${ }^{8}$ and $14.3 \%$ after 15 years in the second series. ${ }^{9}$ The smaller death rate $(14 \%)$ after 15 years in the second series than after 10 years in the first series $(22 \%)$ results from a much higher percentage of melanomas $<7 \mathrm{~mm}$ diameter in the second series. Analysis of these figures reveals that, because the tumour related death rate was nil in both $<7 \mathrm{~mm}$ diameter groups, all metastatic deaths in the $<10 \mathrm{~mm}$ diameter groups had occurred in the $7-<10 \mathrm{~mm}$ diameter groups. Table 1 shows that the tumour related death rates in these two 7-<10 mm diameter groups were $35.5 \%$ and $40.4 \%$ respectively, compared with nil in the two $<7 \mathrm{~mm}$ diameter groups.

One patient with a melanoma $<7 \mathrm{~mm}$ diameter in the series of Thomas et al. ${ }^{9}$ had metastases but had not yet died. Only one case of death from metastases after enucleation in a patient with a melanoma $<7 \mathrm{~mm}$ diameter has been separately reported. ${ }^{\text {"1 }}$ It seems reasonable to postulate that, in general, choroidal melanomas are unlikely to shed cell emboli before they have reached the $7 \mathrm{~mm}$ diameter stage.

\section{Reported results after radiotherapy}

It is relevant at this point to discuss the survival data obtained from patients treated by enucleation and the survival data obtained after treatment by irradiation. Many 10-year or longer follow-up reports on choroidal melanoma patients after enucleation" reveal without exception a tumour related death rate of about $50 \%$. Jensen ${ }^{12}$ published a 25 -year follow-up of 302 patients - with a follow-up percentage of $99.8 \%$ - of whom $51 \%$ had died from metastases. Thus enucleation of eyes containing a melanoma of any size saves half the patients from tumour related death. This figure of $50 \%$ can be improved considerably by enucleating melanoma containing eyes at the earliest stage. We can now detect small melanomas clinically at a much earlier stage than formerly.

It has already been emphasised above that, despite sufficient lapse of time, almost all survival statistics after irradiation are still based on follow-up periods of a few months to no more than three to four years. This holds for the references ${ }^{13-20}$ and for the publications not specifically referred to from these same sources. Although some authors ${ }^{13-16181921}$ claim a longer follow-up period than three to four years, their reports do not permit an assessment of survival after these longer periods. All the above mentioned reports are irrelevant in evaluating the effect of radiation treatment on the survival rate, because tumour related death during the first three to four years after treatment is most likely to be caused by metastases present before the therapy was started. A

Table 1 Follow-up reports on enucleated small choroidal melanomas

\begin{tabular}{|c|c|c|c|c|c|c|}
\hline \multirow{4}{*}{$\begin{array}{l}\text { Diameter } \\
\text { Number } \\
\text { Percentage deaths from metastases }\end{array}$} & \multicolumn{3}{|c|}{$\begin{array}{l}\text { Davidorf et al. }{ }^{8} \\
\text { 10years }\end{array}$} & \multicolumn{3}{|c|}{$\begin{array}{l}\text { Thomas et al. } \\
15 \text { years }\end{array}$} \\
\hline & $<10 \mathrm{~mm}$ & $<7 \mathrm{~mm}$ & $7-10 \mathrm{~mm}$ & $<10 \mathrm{~mm}$ & $<7 \mathrm{~mm}$ & $7-10 \mathrm{~mm}$ \\
\hline & 50 & 18 & 32 & 65 & 42 & 23 \\
\hline & $22 \cdot 7 \%$ & $0 \%$ & $35 \cdot 5 \%$ & $14 \cdot 3 \%$ & $0 \%$ & $40 \cdot 4 \%^{h}$ \\
\hline
\end{tabular}

$a=\frac{50}{32} \times 22 \cdot 7 \% . b=\frac{65}{23} \times 14 \cdot 3 \%$. 
significant difference between the survival rates within the first three to four years post enucleation and post irradiation can be due only to a difference in the selection criteria for treatment.

Char et al. ${ }^{15}$ reported the results of helium ion and proton beam irradiation of choroidal melanomas. Most tumours did not show complete regression, and the mean regression in tumours two years after helium ion irradiation was no more than $31 \%$. It seems justifiable to conclude from these findings that, after two years in the 107 patients in question, $69 \%$ of the irradiated tumour tissue had not regressed. This report indicates once more a certain insensitivity of uveal melanomas to irradiation. It must be appreciated that regression two years after irradiation of even $50 \%$ or $75 \%$ of the original volume can only delay metastatic death by one or two doubling times and cannot prevent eventual death from metastases. Only total regression can save a patient's life if metastases were absent before treatment.

The few papers which are wholly or partially based on a follow-up of more than three to four years include first those of McFaul, ${ }^{22}{ }^{23}$ who reported a longterm clinical study on the eventual outcome of cobalt plaque therapy. The conclusion was that this therapy 'has a limited place in the treatment of choroidal melanoma, because the disease is not readily susceptible to radiation, while the incidence of major complications is high'. The second contribution is that of Lommatzsch, ${ }^{21}$ who claimed that his results for ruthenium radiation were based on a five-year follow-up period. Analysis of this paper reveals, however, that more than $60 \%$ of the patients had actually been followed up for less than five years and in some cases for only six months. This report is therefore of doubtful relevance for the assessment of this form of radiotherapy on the survival rate. Finally, a comparison by Gass ${ }^{24}$ of the prognosis after enucleation vs. cobalt irradiation substantiated the conclusion of McFaul. Survival figures for 27 patients treated by enucleation between June 1967 and June 1976 were compared with those of 21 patients who had been treated with cobalt- 60 episcleral plaques in the same period. The combined number of large and medium sized tumours at the time of treatment was slightly higher in the enucleation group than in the cobalt-60 group. The shortest individual follow-up period was 5.5 years, the longest was 15 years, and the mean follow-up time was 10 years. After enucleation the median survival was $>10$ years; after irradiation it was 3.8 years. Of the enucleated patients, $22 \%$ (six out of 27) had died from metastases against $57 \%$ (12 out of 21) of the irradiated patients. Gass summarised the probability of death from metastases within five years after enucleation as $16 \%$ against $50 \%$ after cobalt irradiation.
Table 2 Histopathology after radiotherapy

\begin{tabular}{|c|c|c|c|}
\hline & Number & $\begin{array}{l}\text { Tumour } \\
\text { necrosis }\end{array}$ & $\begin{array}{l}\text { Viable } \\
\text { tumour }\end{array}$ \\
\hline Char et al. ${ }^{26 *}$ & 4 & 2 & 4 \\
\hline von Domarus et al. ${ }^{27} \dagger$ & 2 & 1 & 2 \\
\hline McFaul et al. ${ }^{25 *}$ & 23 & 6 & 23 \\
\hline Zinn et al. ${ }^{28} \ddagger$ & 1 & 1 & 1 \\
\hline Seddon et al. ${ }^{29} \ddagger$ & 3 & 3 & 3 \\
\hline Charet al. ${ }^{30} \S$ & 3 & 2 & 3 \\
\hline Albert $^{31} \ddagger$ & 1 & 1 & 1 \\
\hline Gass $24 *$ & 5 & 5 & 4 \\
\hline Ferry et al. ${ }^{32} \ddagger$ & 1 & 1 & 1 \\
\hline Total & 43 & 22 & 42 \\
\hline
\end{tabular}

* Cobalt irradiation. $\uparrow$ Ruthenium irradiation.

$\ddagger$ Proton beam irradiation. §Helium ion irradiation.

The great difference in survival after enucleation and irradiation might be explained by the microscopical findings in irradiated melanomas. McFaul and Morgan ${ }^{25}$ found absence of tumour necrosis after cobalt irradiation in 17 out of 23 eyes, while the surrounding ocular tissues showed radiation damage.

Table 2 shows that various types of radiotherapy had failed to destroy the tumour in 42 out of 43 histopathologically studied cases, which in the great majority had come to enucleation in surviving patients. These 43 cases, however, constitute a small fraction of the total number of eyes treated by irradiation and may not show that irradiation had not had a tumoricidal effect in the non-enucleated cases. The true success or failure of irradiation can be evaluated only by a long-term follow-up period. The only globe in which no viable tumour tissue is reported is included in the series published by Gass, ${ }^{24}$ who did not provide detailed histopathological descriptions. It is noteworthy that $50 \%$ of the microscopically studied irradiated melanomas did not show any evidence of necrosis.

Two clinicopathological case reports ${ }^{334}$ claim successful treatment by irradiation. However, Grizzard et al.$^{33}$ describe an incomplete eye, while Cleasby and Kutzscher ${ }^{34}$ present a one-sentence microscopic description of a choroidal mass, of which only one low-power $(\times 25)$ microphotograph of an unbleached section without any cellular detail is reproduced.

It is obvious that further dissemination is excluded with certainty after enucleation. After irradiation, on the contrary, the risk of dissemination will again increase exponentially in the great majority of cases if the tumour continues to grow.

Van Peperzeel ${ }^{35}$ has stressed that melanoma cells have a greater ability than most other tumour cells to repair the potential lethal damage induced by radiotherapy. This author also emphasised the accepted fact that poorly oxygenated tumour cells are 
generally less sensitive to irradiation than well oxygenated tumour cells. It is likely that a large proportion of the cells in a choroidal melanoma are poorly oxygenated. This condition thus requires high daily radiation fractions, which cause severe late damage to the normal tissue in the irradiated area.

Advocates of radiation therapy advance as their main argument the 'fight for sight' principle. The justification is that they are helping patients who can see only with the tumour containing eye. However, many patients with a healthy, functioning other eye have also been treated by irradiation. It appears that the minor visual results of this 'fight for sight', by which the patient's life is seriously endangered, do not justify the risk of unnecessary death from metastases. Lommatzsch ${ }^{21}$ found five years after treatment a best visual acuity of $\geqslant 0.5$ in 18 out of 205 irradiated eyes $(8 \cdot 8 \%)$. Gass ${ }^{24}$ reported that in 15 out of 21 irradiated eyes $\geqslant 2$ lines of acuity were lost and that nine of these 15 patients with $\geqslant 0.5$ visual acuity at the time of treatment had $\leqslant 0 \cdot 1$ visual acuity at the last examination. It is necessary to reiterate that only nine out of the 21 irradiated patients in Gass's series had not died from metastases at the time the survival data were analysed.

An ideal conservative treatment should (1) eradicate the tumour, (2) retain the intact eye without prejudice to the chance of survival, and (3) preserve useful vision. ${ }^{23}$ It is probable that none of the available radiation techniques comes up to even one of these requirements.

The present analysis indicates that patients with irradiated choroidal melanomas run the same risks that those patients with photocoagulated melanomas have incurred in the past. It has taken 20 years for Vogel $^{36}$ to be able to state that photocoagulation 'was effective only in very few specific cases'. Photocoagulation remained an experimental form of treatment for those 20 years, because no conclusive long-term results were produced. Radiotherapy has not been justified so far by any relevant long-term survival statistic. On the contrary, basic oncological knowledge, all the 10-25-year survival statistics after enucleation, and the few relevant long-term statistics after irradiation ${ }^{2-24}$ indicate that it is medically unjustified to recommend radiotherapy to patients with a choroidal melanoma and a healthy, functioning contralateral eye. The few justifiable exceptions are elderly patients with a short life expectancy and patients who refuse enucleation. The other patients have the right to be treated by enucleation, which eliminates any further dissemination. This holds especially also for patients with small melanomas: metastatic death after enucleation of $<7 \mathrm{~mm}$ diameter melanomas is a great rarity, but occurs in about $40 \%$ of cases within the $7-10 \mathrm{~mm}$ diameter size group. It is to be stressed that histopathological examination of 171 eyes, enucleated in the treatment of melanomas $<10 \mathrm{~mm}$ diameter, ${ }^{89}{ }^{37}$ has confirmed the clinical diagnosis of malignant melanoma in every case. The risk of unnecessary enucleation in cases of small melanomas therefore appears to be negligible.

Seigel et al..$^{38}$ emphasised that, to make therapeutic progress, alternative treatments must be evaluated with well designed clinical trials or we run the risk of continuing to support inferences with inadequate studies and clinical impressions. It is justifiable to argue that it is a serious and urgent matter that those cases which have been treated by irradiation should be carefully documented and that long-term followup survival and functional data for irradiated uveal melanomas be published for every individual patient. Tumour related death after enucleation appeared to decrease steadily to a low percentage in the second five-year follow-up period. Our knowledge of tumour biology suggests that, after irradiation which is unsuccessful in achieving complete tumour regression, the remaining tumour tissue will continue its exponential growth. In these cases dissemination and the death rate from metastases will tend to increase exponentially in this same second five-year follow-up period. Irradiation of choroidal melanomas is still a medical experiment in which patients incur a progressive risk of death from metastases three to four years after the therapy has started.

The authors thank Professor W R Lee for his help in the preparation of the manuscript.

\section{References}

1 Collins VP, Loeffler RK, Tivey H. Observations on growth rates of human tumors. Am J Roentgenol 1956; 76: 988-1000.

2 Rümke P, Bernheim J, van der Vorm DH, van Peperzeel HA, Looysen R. Effect of BCG stimulation on the growth rate of pulmonary metastases in 3 patients with melanoma. Recent Results Cancer Res 1974; 47: 470-2.

3 Rampen FHJ. Malignant melanoma. Sex differences in response to chemotherapy. Eur J Clin Oncol 1982; 18: 107-10.

4 Manschot WA, van Peperzeel HA. Choroidal melanoma. Enucleation or observation? A new approach. Arch Ophthalmol 1980; 98: 71-7.

5 Packer S. The management of choroidal melanoma. Arch Ophthalmol 1984; 102: 1450-2.

6 Gass JDM. Comparison of uveal melanoma growth rates with mitotic index and mortality. Arch Ophthalmol 1985; 103: 924-31.

7 Zimmerman LE, McLean IW, Foster WD. Does enucleation of an eye containing a malignant melanoma prevent or acceleratc the dissemination of tumour cells? Br J Ophthalmol 1978; 62: $420-5$.

8 Davidorf FA, Lang JR. The natural history of malignant melanoma of the choroid: small vs large tumors. Ophthalmology (Rochester) 1975; 79: 310-20.

9 Thomas JV, Green R, Maumence AE. Small choroidal melanomas. A long-term follow-up study. Arch Ophthalmol 1979; 97: 861-4.

10 Barr CC, Sipperley JO, Nicholson DH. Small melanomas of the choroid. Arch Ophthalmol 1978; 96: 1580-2. 
11 Manschot WA. The natural history of uveal melanomas and its therapeutic consequences. Doc Ophthalmol 1980; 50: 83-98.

12 Jensen OA. Malignant melanomas of the human uvea: 25-year follow-up of cases in Denmark, 1943-1952. Acta Ophthalmol (Kbh) 1982; 60: 161-82.

13 Gragoudas ES, Goitein M, Verhey I, et al. Proton beam irradiation of uveal melanomas. Results of 51/2-year study. Arch Ophthalmol 1982; 100: 928-34.

14 Shields JA, Augsburger JJ, Brady LW, Day JL. Cobalt plaque therapy of posterior uveal melanomas. Ophthalmology (Rochester) 1982; 89: 1201-7.

15 Char DH, Saunders WM, Gragoudas ES. Charged particle (helium ion and proton) therapy. Ophthalmic Forum 1983; 1: 42-4.

16 Cruess AF, Augsburger JJ, Shields JA, Donoso LA, Amsel J. Visual results following cobalt plaque radiotherapy for posterior uveal melanomas. Ophthalmology (Rochester) 1984; 91: 131-6.

17 Packer S, Rotman M, Salanitro P. Iodine-125 irradiation of choroidal melanoma, clinical experience. Ophthalmology (Rochester) 1984; 91: 1700-12.

18 Seddon JM, Gragoudas ES, Albert DM, Hsieh CC, Polivogianis L, Friedenberg R. Comparison of survival rates for patients with uveal melanoma after treatment with proton beam irradiation or enucleation. Am J Ophthalmol 1985; 99: 282-90.

19 Zografos L, Perret C, Gailloud C, von Essen C, Jaccard S. Conservative treatment of melanomas of the choroid by proton beam. Proceedings of the 7th Congress of the European Society of Ophthalmology, Helsinki, 1985: 468-70.

20 Foerster MH, Bornfeld N, Wessing A, Schulz U, Schmitt G, Meyer-Schwickenrath G. Die Behandlung von malignen Melanomen der Uvea mit 106-Ruthenium-Applikatoren. Klin Monatsbl Augenheilkd 1984; 185: 490-4.

21 Lommatzsch PK. $\beta$-Irradiation of choroidal melanoma with ${ }^{106} \mathrm{Ru} /{ }^{106} \mathrm{Rh}$ applicators: 16 years' experience. Arch Ophthalmol 1983; 101: 713-7.

22 McFaul PA. Local radiotherapy in the treatment of malignant melanoma of the choroid. Trans Ophthalmol Soc UK 1978; 97: 421-7.

$23 \mathrm{McF}$ aul PA. The place of radiotherapy in the treatment of uveal melanoma. Doc Ophthalmol 1980; 50: 63-9.

24 Gass JDM. Comparison of prognosis after enucleation vs cobalt 60 irradiation of melanomas. Arch Ophthalmol 1985; 103: 916-23.

25 McFaul PA, Morgan G. Histopathological changes in malignant melanomas of the choroid after cobalt plaque therapy. $\mathrm{Br} J$ Ophthalmol 1977; 61: 221-8.

26 Char DH, Lonn LE, Margolis LW. Complications of cobalt plaque therapy of choroidal melanomas. Am J Ophthalmol 1977; 84: 536-41.

27 von Domarus D, Hallerman D. Histologische Befunde nach Therapie mit dem ${ }^{106} \mathrm{Ru} /{ }^{106} \mathrm{Rh}$-Applikator. Ber Zusammenkunft Dtsch Ophthalmol Ges 1979; 76: 185-8.

28 Zinn KM, Stein-Pokorny K, Jakobiec FA, Friedman AH, Gragoudas ES, Ritch R. Proton beam irradiated epithelioid cell melanoma of the ciliary body. Ophthalmology (Rochester) 1981; 88: $1315-21$.

29 Seddon JM, Gragoudas ES, Albert DM. Ciliary body and choroidal melanomas treated by proton beam irradiation. Arch Ophthalmol 1983; 101: 1402-8.

30 Char DH, Crawford JB, Castro JR, Woodruff KH. Failure of choroidal melanoma to respond to helium ion therapy. Arch Ophthalmol 1983; 101: 236-41.

31 Albert DM. Proton beam treated ocular melanoma. Read before European Ophthalmological Pathology Society, Groningen, Netherlands, 18 May 1983.

32 Ferry AP, Blair CJ, Gragoudas ES, Volk SC. Pathologic examination of ciliary body melanoma treated with proton beam irradiation. Arch Ophthalmol 1985; 103: 1849-53.

33 Grizzard WS, Torczynski E, Char DH. Helium ion charged particle therapy for choroidal melanoma. Histopathologic findings in a successfully treated patient. Arch Ophthalmol 1984; 102: 576-8.

34 Cleasby GW, Kutzscher BM. Clinicopathologic report of successful cobalt 60 plaque therapy for choroidal melanoma. $\mathrm{Am}$ J Ophthalmol 1985; 100: 828-30.

35 van Peperzeel HA. Treatment of retinoblastoma and choroidal melanoma. A multidisciplinary approach. Int Ophthalmol 1985; 7:255-8.

$36 \mathrm{Vogel} \mathrm{MH}$. The application of photocoagulation in the treatment of malignant melanoma of the choroid. Ophthalmic Forum 1983; 1: 46-7.

37 de Wolff-Rouendaal D, Oosterhuis JA. Histology of small melanomas. Doc Ophthalmol 1980; 50: 21-6.

38 Seigel D, Myers M, Ferris F, Steinhorn SC. Survival rates after enucleation of eycs with malignant melanoma. Am J Ophthalmol 1979; 87: 761-5.

Accepted for publication 3 July 1986. 